\title{
Riemerella columbina sp. nov., a bacterium associated with respiratory disease in pigeons
}

\author{
M. Vancanneyt, ${ }^{1}$ P. Vandamme, ${ }^{2,3}$ P. Segers, ${ }^{2}$ U. Torck, ${ }^{2}$ R. Coopman, ${ }^{2}$ \\ K. Kersters ${ }^{2}$ and K.-H. Hinz ${ }^{4}$
}

Author for correspondence: M. Vancanneyt. Tel: +329 2645115. Fax: +3292645092.

e-mail: Marc.Vancanneyt@rug.ac.be

1,2 BCCM/LMG Culture

Collection ${ }^{1}$, and

Laboratory of

Microbiology2,

Ledeganckstraat 35 ,

University of Ghent, B-

9000 Ghent, Belgium

3 Department of Medical Microbiology, University Hospital, Antwerp. Belgium

4 Clinic for Poultry, School of Veterinary Medicine Hannover, Hannover, Germany

\begin{abstract}
Thirteen Gram-negative bacterial isolates were recovered from diseased pigeons and were tentatively classified as Riemerella anatipestifer-like strains based on conventional phenotypic features and disease symptoms. Phenotypic characteristics that differentiated the pigeon isolates from $R$. anatipestifer included their greyish-white to beige pigment formation on Columbia blood agar and the hydrolysis of aesculin. Furthermore, $R$. anatipestifer strains have thus far not been reported in pigeons. The phenotypic differences together with the unique host range of the new isolates have prompted the inclusion of these strains in a polyphasic taxonomic study. Extensive phenotypic examination, PAGE of total proteins and GC analysis of fatty acid contents revealed that the pigeon isolates constitute a homogeneous cluster, distinct from the $R$. anatipestifer reference strains. The phylogenetic position of representative strains was examined by using DNA-rRNA hybridizations and indicated that this taxon belongs to the genus Riemerella. Finally, DNA-binding values confirmed that the strains constitute a separate species for which the name Riemerella columbina sp. nov. is proposed. Strain LMG $11607^{\top}$ was selected as the type strain. Clinical observations suggest that these organisms are involved in pathogenesis of respiratory diseases, similar to those associated with $\boldsymbol{R}$. anatipestifer infections. However, the role of co-factors and the interaction with other agents are unknown.
\end{abstract}

Keywords: Riemerella columbina sp. nov., identification, polyphasic taxonomy

\section{INTRODUCTION}

Riemerella anatipestifer strains have been isolated worldwide from domestic and wild birds. The organism causes a disease named exudative septicaemia (Riemer, 1904) which particularly affects ducks, less frequently geese and turkeys, and sporadically chickens and wild birds (Brodgen, 1989; Hinz et al., $1998 \mathrm{~b}$ ). The organism was previously referred to as [Moraxella] anatipestifer or [Pasteurella] anatipestifer and considered a species incertae sedis in Bergey's Manual of Systematic Bacteriology (Bøvre, 1984; Mannheim, 1984). Piechulla and co-workers denoted for the first time the correct affiliation within the Flavobacterium-Cytophaga group (Piechulla et al., 1986). In 1991, Rossau and co-workers reported similarities between the latter group and $[M$.$] anati-$ pestifer, i.e. the lack of flagellation, the low DNA base

Abbreviation: BSS, buffered single substrate. ratio, the presence of menaquinones as sole respiratory quinones and the presence of branched-chain fatty acids in high percentages, the absence of carbohydrate fermentation and a similar pattern of hydrolytic enzymes (Rossau et al., 1991). Finally, in 1993, the species was reclassified in a newly described genus, Riemerella, based not only on its genomic divergence from allied taxa within rRNA superfamily $V$, but also on a number of unique chemotaxonomic and phenotypic properties, including its capnophilic metabolism, the absence of pigments and its fatty acid and menaquinone content (Segers et al., 1993). 16S rRNA gene sequence analysis confirmed the phylogenetic position of Riemerella anatipestifer as a separate branch within the Flavobacterium-Cytophaga group (Subramaniam et al., 1997). At present, $R$. anatipestifer is the only validly described species of the genus.

One of us (K.-H.H.) examined 13 strains from diseased pigeons and tentatively identified them as $R$. anatipestifer-like strains. In the present study, we performed 
a polyphasic taxonomic study to clarify the taxonomic position of these strains. Below, we show that these isolates constitute a novel Riemerella species, for which we propose the name Riemerella columbina sp. nov.

\section{METHODS}

Bacterial strains and growth conditions. Data on the origin of the strains are listed in Table 1. $R$. columbina strains were grown and maintained on Trypticase Soy agar (BBL) and incubated at $36-37^{\circ} \mathrm{C}$ in a microaerobic atmosphere containing approximately $5 \% \mathrm{O}_{2}, 3.5 \% \mathrm{CO}_{2}, 7 \cdot 5 \% \mathrm{H}_{2}$ and $84 \% \mathrm{~N}_{2}$, unless stated otherwise. Bacteriological purity was checked by plating and examining living and Gram-stained cells.

Fatty acid methyl ester analysis. All strains were grown for $48 \mathrm{~h}$ on one or two Petri dishes. A loopful of well-grown cells was harvested; preparation, separation, identification and numerical comparison of the fatty acid methyl esters were performed using the Microbial Identification System (Microbial ID) as described before (Vandamme et al., 1992).
PAGE of whole-cell proteins. After incubation of cells for $48 \mathrm{~h}$, whole-cell protein extracts were prepared, and SDSPAGE was performed as described by Pot et al. (1994). A densitometric analysis, normalization and interpolation of the protein profiles, and a numerical analysis were performed by using the Gelcompar software package version 4.0 (Applied Maths, Kortrijk, Belgium).

Preparation of high-molecular-mass DNA. High-molecularmass native DNA was prepared as described before (Vandamme et al., 1992).

DNA base compositions. All of the mean mol $\% \mathrm{G}+\mathrm{C}$ values were determined by thermal denaturation and calculated by using the equation of Marmur \& Doty (1962), as modified by De Ley (1970).

DNA-DNA hybridization experiments. The degree of DNA-DNA binding, expressed as a percentage, was determined spectrophotometrically by the initial renaturation rate method of De Ley et al. (1970). Each value is the mean of at least two hybridization experiments. Values of $30 \%$ DNA binding and less do not represent significant DNA homology. The total DNA concentration was about $59 \cdot 3 \mu \mathrm{g}$

\section{Table 1. Strains studied}

Type strains are indicated by a superscript T. CCUG, Culture Collection of the University of Göteborg, Department of Clinical Bacteriology, University of Göteborg, Göteborg, Sweden; Hinz, K.-H. Hinz, Clinic for Poultry, School of Veterinary Medicine Hannover, Hannover, Germany; Hommez, J. Hommez, Provinciaal Verbond voor Dierenziektenbestrijding, Torhout, Belgium; Köhler, B. Köhler, Staatliches Veterinär- und Lebensmitteluntersuchungsamt, Potsdam, Germany; LMG, BCCM/LMG Culture Collection Laboratorium voor Microbiologie, University of Ghent, Ghent, Belgium; MCCM, Medical Culture Collection of Microorganisms, Marburg, Germany.

\begin{tabular}{|c|c|c|c|}
\hline Name & Strain no. & $\begin{array}{l}\text { Other strain } \\
\text { designation }\end{array}$ & $\begin{array}{c}\text { Source and place } \\
\text { of isolation }\end{array}$ \\
\hline Riemerella anatipestifer & LMG 10957 & Hommez 3-8 & Duck, Belgium \\
\hline Riemerella anatipestifer & LMG 10988 & Hommez 5-25 & Chicken, Belgium \\
\hline Riemerella anatipestifer & LMG $11054^{\mathrm{T}}$ & CCUG $14215^{\mathrm{T}}$ & Duck blood, USA \\
\hline Riemerella anatipestifer & LMG 11056 & CCUG 25000 & Duck, UK, 1966-1969 \\
\hline Riemerella anatipestifer & LMG 11059 & CCUG 25005 & Duck, UK, 1966-1969 \\
\hline Riemerella anatipestifer & LMG 11060 & CCUG 25054 & \\
\hline Riemerella anatipestifer & LMG 11146 & CCUG 21370 & Duck blood, USA \\
\hline Riemerella anatipestifer & LMG 11601 & MCCM 00762 & Duck, Germany, 1985 \\
\hline Riemerella anatipestifer & LMG 11602 & MCCM 00771 & Goose, Germany, 1985 \\
\hline Riemerella anatipestifer & LMG 11603 & MCCM 00772 & USA \\
\hline Riemerella anatipestifer & LMG 11605 & MCCM 00793 & Duck, Germany, 1981 \\
\hline Riemerella columbina & LMG $11607^{\mathrm{T}}$ & Hinz $x 183-89^{T}$ & Pigeon palatine cleft, Germany \\
\hline Riemerella columbina & LMG 11608 & Hinz $\times 220-90$ & Pigeon palatine cleft, Germany \\
\hline Riemerella columbina & LMG 12983 & Hinz $\times 520-82$ & Pigeon lung, Germany \\
\hline Riemerella columbina & LMG 12987 & Hinz x296-83 & Pigeon trachea, Germany \\
\hline Riemerella columbina & LMG 15723 & Hinz $x 163-90$ & Pigeon lung, Germany \\
\hline Riemerella columbina & LMG 15724 & Hinz $x 100-90$ & Pigeon palatine cleft, Germany \\
\hline Riemerella columbina & LMG 16900 & Köhler G 1844-95 & $\begin{array}{l}\text { Internal and respiratory organs } \\
\text { of pigeon, Germany }\end{array}$ \\
\hline Riemerella columbina & LMG 18232 & Köhler G 1024-94 & Pigeon brain, Germany \\
\hline Riemerella columbina & LMG 18233 & Köhler G 1274-94 & Pigeon trachea, Germany \\
\hline Riemerella columbina & LMG 18234 & Köhler G 1844-95 & Pigeon trachea, Germany \\
\hline Riemerella columbina & LMG 18235 & Köhler G 704-97 & Pigeon airsac fibrin, Germany \\
\hline Riemerella columbina & LMG 18236 & Köhler G 1009-97 & Pigeon lung, Germany \\
\hline Riemerella columbina & LMG 18237 & Köhler G 1364-97 & Pigeon trachea, Germany \\
\hline
\end{tabular}


$\mathrm{ml}^{-1}$, and the optimal renaturation temperature in $1 \times \mathrm{SSC}$ was $60.8^{\circ} \mathrm{C}$.

DNA-rRNA hybridization experiments. ${ }^{3} \mathrm{H}$-labelled rRNA of the type strain of $R$. anatipestifer was isolated and purified as reported earlier (Segers et al., 1993). Hybridization between the rRNA probe and single-stranded filter-fixed DNA of $R$. columbina LMG $11607^{\mathrm{T}}$ and LMG 11608 was carried out as described previously by Van Landschoot \& De Ley (1983). Each DNA-rRNA hybrid was characterized by the $T_{m(e)}$ value (the temperature at which half of the DNA-rRNA hybrid is thermally denatured).

Phenotypic tests. Strains were grown on Columbia agar base (Oxoid) supplemented with 7\% defibrinated sheep blood unless stated otherwise. Growth was evaluated aerobically and anaerobically at $37^{\circ} \mathrm{C}$ and microaerobically at 24,37 and $42{ }^{\circ} \mathrm{C}$. Growth tests on MacConkey agar and on litmus lactose agar, capsule and flagella staining, and motility were performed as described by Vandamme et al. (1998).

Cells used as inocula for conventional biochemical tests were grown for 16-24 h under microaerobic conditions in a moist chamber. Bacteria were suspended in $0 \cdot 15 \mathrm{M} \mathrm{NaCl}$ solution, $\mathrm{pH} 7 \cdot 0 \pm 1$, to a concentration of about $10^{8}$ viable bacterial cells. Growth was recorded daily at least up to $3 \mathrm{~d}$. Oxidation and fermentation of glucose, aesculin and gelatin hydrolysis, determination of oxidase, catalase, urease and arginine dihydrolase activity, nitrate reduction, hyaluronidase and chondroitin sulfatase activity and Voges-Proskauer test were performed as described by Vandamme et al. (1998).

The API 20NE, API ZYM and API ID32E microtest systems were used according to the recommendations of the manufacturer (bioMérieux).

The buffered single substrate (BSS) test was used for the detection of a weak acidification of carbohydrates (using conventional phenotypic tests, acid production may be masked by accumulation of alkaline breakdown products of complex medium components as, for example, peptone). The base medium consisted of buffered saline ( $\mathrm{KH}_{2} \mathrm{PO}_{4}$, $0.1 \% ; \mathrm{K}_{2} \mathrm{HPO}_{4}, 0.1 \% ; \mathrm{NaCl}, 0.5 \% ; \mathrm{pH} 7.6$ ) containing $2 \%$ carbohydrate and phenol red in a final concentration of $1: 50000$ as indicator (Lautrop, 1960). A heavy inoculum ( $100 \mu$ l of a suspension of about $400 \mathrm{mg}$ wet bacterial mass in $2 \mathrm{ml} 0.15 \mathrm{M} \mathrm{NaCl}$ solution) was added to $0.5 \mathrm{ml}$ of buffered carbohydrate solution in a tube with a diameter of $7 \mathrm{~mm}$. The reactions were read after 6 and $24 \mathrm{~h}$ incubation in a water bath at $37^{\circ} \mathrm{C}$. Uninoculated carbohydrate-containing media and inoculated media without carbohydrate were incubated as controls. The reactions were recorded as weak positive if the $\mathrm{pH}$ values were $7 \cdot 1-6 \cdot 9$ (orange-coloured reaction) and positive if the $\mathrm{pH}$ decreased to 6.8 or lower (yellow-coloured reaction).

Sensitivity to antimicrobial drugs was tested under standard conditions on D.S.T. agar (Oxoid), supplemented with $5 \%$ defibrinated sheep blood, by using the antimicrobial susceptibility test discs from Oxoid. Plates were incubated microaerobically at $37^{\circ} \mathrm{C}$ for $16-18 \mathrm{~h}$. A zone of inhibition of more than $1 \mathrm{~mm}$ was recorded as a positive test result and was interpreted as 'in vitro susceptible'.

\section{RESULTS}

\section{Isolation procedures and pathology}

The 13 strains studied were isolated from the airsac, lung, palatine cleft, trachea or brain of pigeons (Table 1). The birds suffered from airsacculitis, tracheitis, pneumonia, hepatitis and/or other lesions similar to those of the $R$. anatipestifer-associated exudative septicaemia. In some cases, an additional infection with coccidia (LMG 18236), capillaria (LMG 18236), paramyxovirus (LMG 18234, LMG 18236) or Salmonella (LMG 18237) was observed.

\section{Phenotypic characterization}

From a large set of conventional phenotypic tests, only two features clearly differentiated all $R$. columbina strains examined from $R$. anatipestifer reference strains: pigment formation and aesculin hydrolysis. A further extensive phenotypic characterization using API galleries (API 20NE, API ID32E, API ZYM) and the BSS test did not yield additional characters for distinguishing both taxa unequivocally (see below).

Out of six strains examined, all six were susceptible to $10 \mu \mathrm{g}$ ampicillin, $15 \mu \mathrm{g}$ erythromycin and $10 \mu \mathrm{g}$ penicillin, and four of them were sensitive to $30 \mu \mathrm{g}$ oxytetracycline. In addition, all strains were resistant to $100 \mu \mathrm{g}$ nitrofurantoin, $10 \mu \mathrm{g}$ gentamicin, $10 \mu \mathrm{g}$ neomycin and sulfonamides.

\section{GC analysis of methylated fatty acids}

The cellular fatty acid compositions of Riemerella strains are shown in Table 2. Major fatty acids for all strains were the branched-chain fatty acids 13:0 iso, $15: 0$ iso, $15: 0$ anteiso, $15: 0$ iso $3-\mathrm{OH}$ and $17: 0$ iso $3-$ $\mathrm{OH}$. Based on the relative amounts of these dominant features, and on the presence of some minor peaks, $R$. columbina strains were easily differentiated from reference strains of $R$. anatipestifer. Strains of the latter taxon were characterized by the presence of significantly lower amounts of $15: 0$ anteiso $(5 \%$ versus $22 \%)$ and higher amounts of $15: 0$ iso $(52 \%$ versus $45 \%), 15: 0$ iso $3-\mathrm{OH}(8 \%$ versus $4 \%$ ) and $17: 0$ iso $3-$ $\mathrm{OH}(14 \%$ versus $7 \%)$. Furthermore, only $R$. columbina strains contained appreciable amounts of $13: 0$ anteiso $(2 \%), 17: 02-\mathrm{OH}(1 \%)$ and 'summed feature 4' (3\%; for explanation see Table 2$)$.

\section{PAGE of whole-cell proteins}

Duplicate protein extracts were prepared to check the reproducibility of the growth conditions and the preparation of the extracts. The correlation level between duplicate protein patterns was $r \geqslant 0.95$.

The whole-cell protein profiles of the $R$. columbina strains were analysed together with those of reference strains of $R$. anatipestifer. The whole-cell protein profiles and the corresponding dendrogram obtained after average-linkage cluster analysis are shown in Fig. 1. At a correlation coefficient of 0.71 , two clusters (I and II) were delineated. All $R$. columbina strains grouped in cluster I at a level $r \geqslant 0.75$, and $R$. anatipestifer strains constituted a second cluster (II) at $r \geqslant 0 \cdot 78$. 
Table 2. Fatty acid composition of Riemerella species

All strains listed in Table 1 were investigated. Fatty acids that accounted for less than $1.0 \%$ of the total fatty acids in all of the strains studied are not shown. TR, Trace (less than $1.0 \%$ ); ND, not detected.

\begin{tabular}{|c|c|c|c|c|c|c|c|c|c|c|c|}
\hline Species & $13: 0$ iso & $13: 0$ anteiso & $\mathrm{UN}^{*} 13.566$ & $14: 0$ iso & $15: 02-\mathrm{OH}$ & $15: 0$ iso & $15: 0$ anteiso & $15: 0$ iso $3-O H$ & $17: 02-\mathrm{OH}$ & $17: 0$ iso $3-\mathrm{OH}$ & $\begin{array}{l}\text { Summed } \\
\text { feature } 4 \dagger\end{array}$ \\
\hline$R$. anatipestifer & $15 \cdot 1 \pm 3 \cdot 8$ & TR & $1.4 \pm 0.5$ & TR & TR & $52 \cdot 4 \pm 4 \cdot 6$ & $5 \cdot 4 \pm 1 \cdot 1$ & $8 \cdot 2 \pm 2 \cdot 4$ & ND & $13 \cdot 6 \pm 3 \cdot 4$ & ND \\
\hline R. columbina & $10 \cdot 1 \pm 1 \cdot 8$ & $2 \cdot 0 \pm 0.7$ & $\mathrm{TR}$ & $1 \cdot 0 \pm 0 \cdot 2$ & $1 \cdot 0 \pm 0.4$ & $45 \cdot 3 \pm 3 \cdot 3$ & $22 \cdot 1 \pm 3 \cdot 3$ & $3.9 \pm 0.9$ & $1 \cdot 0 \pm 0 \cdot 1$ & $7 \cdot 0 \pm 1 \cdot 5$ & $2 \cdot 9 \pm 1 \cdot 3$ \\
\hline
\end{tabular}

* ECL, equivalent chain-length. The identity of the fatty acid is not known.

† Summed feature 4 consisted of one or more of the following fatty acids which could not be separated by the Microbial Identification

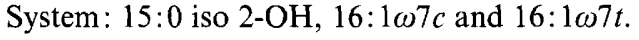
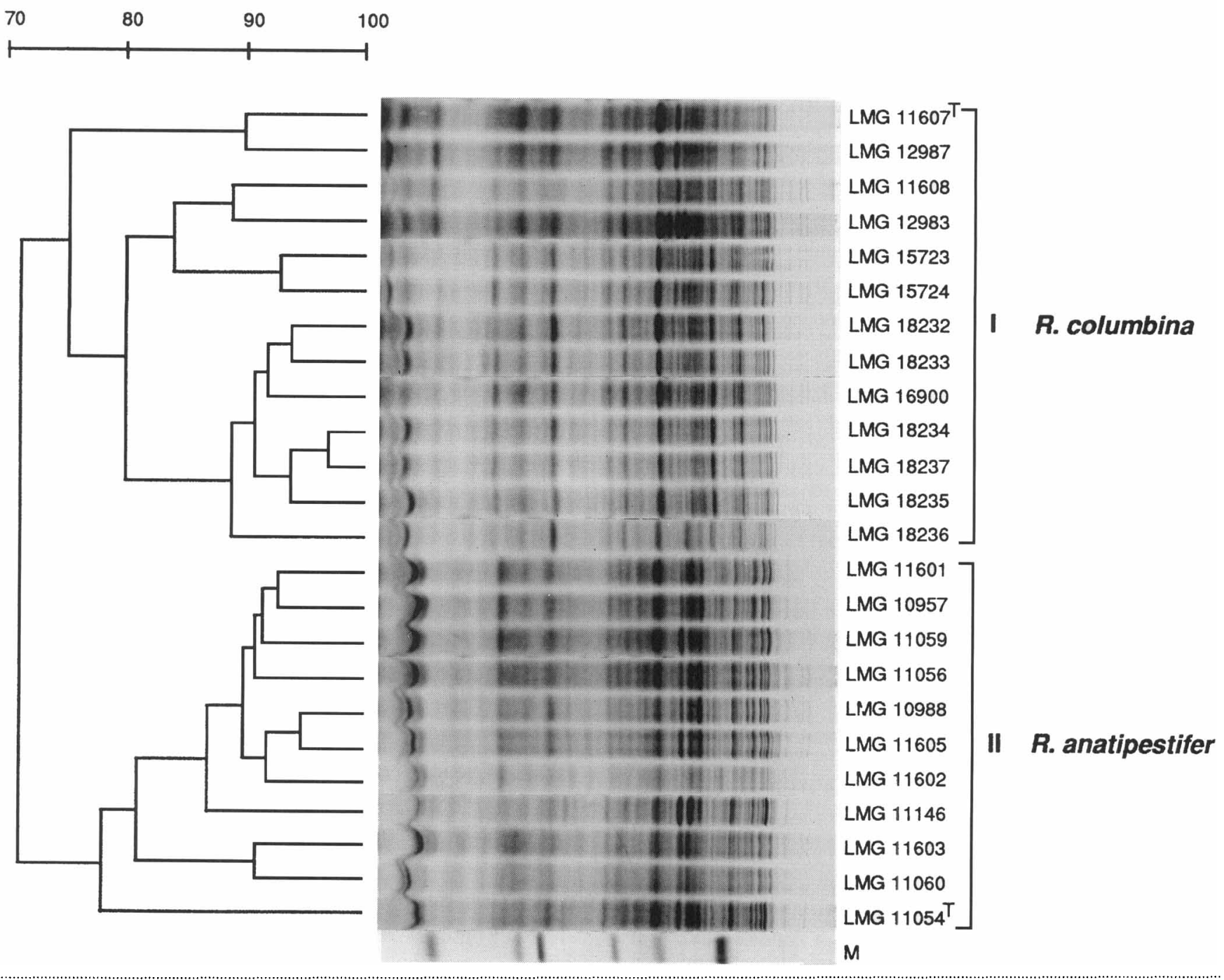

Fig. 1. Protein profiles of Riemerella strains listed and corresponding dendrogram derived from the unweighted pair group average linkage of correlation coefficients $r$ (expressed for convenience as a percentage value). The positions of the molecular mass markers (track labelled M) are indicated from left to right: trypsin inhibitor, $20100 \mathrm{Da}$; trypsinogen, $24000 \mathrm{Da}$; carbonic anhydrase, $29000 \mathrm{Da}$; glyceraldehyde-3-phosphate dehydrogenase, $36000 \mathrm{Da}$; egg albumin, $45000 \mathrm{Da}$; and bovine albumin, $66000 \mathrm{Da}$. 


\section{DNA-DNA hybridizations}

DNA-DNA hybridization data revealed that the $R$. columbina strains LMG 11608 and LMG 16900 exhibited DNA-binding values of, respectively, 89 and $100 \%$ with the type strain LMG $11607^{\mathrm{T}}$. No significant DNA relatedness $(12 \%)$ was measured between the type strain of $R$. columbina and $R$. anatipestifer.

\section{DNA base compositions}

Determination of the DNA base composition yielded $\mathrm{G}+\mathrm{C}$ contents between 36 and $37 \mathrm{~mol} \%$ for the three R. columbina strains studied (LMG $11607^{\mathrm{T}}$, LMG 11608 and LMG 16900). A G + C value of $35 \mathrm{~mol} \%$ was obtained for the type strain of $R$. anatipestifer.

\section{DNA-rRNA hybridizations}

DNA-rRNA hybridization experiments were performed with rRNA from the type strain of $R$. anatipestifer LMG $11054^{\mathrm{T}}$ and DNA from, respectively, $R$. columbina LMG $11607^{\mathrm{T}}$ and LMG 11608. Small differences in melting temperatures $\left[T_{\mathrm{m}(\mathrm{e})}\right]$ of $1-2{ }^{\circ} \mathrm{C}$ differentiated $R$. columbina from $R$. anatipestifer strains.

\section{DISCUSSION}

Thirteen strains isolated from diseased pigeons were investigated using a number of conventional phenotypic tests and were tentatively identified as $R$. anatipestifer-like strains. Only few tests differentiated the latter strains from $R$. anatipestifer. Colonies of all $R$. anatipestifer-like strains showed a greyish-white to beige pigmentation on Columbia blood agar, whereas those of $R$. anatipestifer were nonpigmented. Furthermore, the new isolates differed from the latter species by their ability to hydrolyse aesculin. In addition, the unique source of the isolates (available literature data indicate that $R$. anatipestifer strains were not previously isolated from pigeons) also prompted us to compare these pigeon isolates in a polyphasic approach with $R$. anatipestifer reference strains to determine if both groups of strains represented separate taxonomic units.

The fatty acid compositions of all strains were determined to evaluate the usefulness of this characteristic for differentiation and identification of both taxa (Table 2). A similar overall fatty acid content was observed for all strains. Dominant fatty acids were $13: 0$ iso, $15: 0$ iso, $15: 0$ anteiso, $15: 0$ iso $3-\mathrm{OH}$ and 17:0 iso 3-OH. $R$. anatipestifer yielded higher amounts of $13: 0$ iso, $15: 0$ iso, $15: 0$ iso $3-\mathrm{OH}$ and $17: 0$ iso $3-\mathrm{OH}$ and a significantly lower amount of 15:0 anteiso. Characteristic for $R$. anatipestifer-like strains was the presence of small but significant relative amounts of 13:0 anteiso, 17:0 2-OH and 'summed feature 4'.

All strains listed in Table 1 were further compared by using SDS-PAGE of whole-cell proteins (Fig. 1). Two major clusters were identified grouping $13 R$. anati- pestifer-like strains (cluster $\mathrm{I} ; r \geqslant 0.75)$ and $11 R$. anatipestifer reference strains (cluster II; $r \geqslant 0.78$ ), respectively. Based on these data, strains were selected for DNA-DNA hybridization experiments. Among the $R$. anatipestifer-like strains, DNA-binding values of, respectively, $89 \%$ and $100 \%$ were observed between strain LMG $11607^{\mathrm{T}}$ and strains LMG 11608 and LMG 16900. No significant DNA relatedness was measured between strains of the latter taxon and the type strain of $R$. anatipestifer.

These phenotypic, chemotaxonomic and genomic data demonstrated that the pigeon strains constitute a homogeneous group and should be allocated to a new species. A further extensive phenotypic study was performed to look for additional features for distinguishing both taxa. As for R. anatipestifer, also the new species was characterized by the absence of a large number of biochemical properties (see below).

The phylogenetic affiliations of two representative strains of $R$. anatipestifer-like strains, LMG $11607^{\mathrm{T}}$ and LMG 11608, were determined by using DNA-rRNA hybridization experiments. These data demonstrated that both strains are highly related to $R$. anatipestifer, differing only in $T_{\mathrm{m}(\mathrm{e})}$ values of $1-2^{\circ} \mathrm{C}$ and clearly indicating that both species belong to a single genus. DNA base compositions of representative strains were determined and values between 36 and $37 \mathrm{~mol} \% \mathrm{G}+\mathrm{C}$ were detected. This DNA base content is slightly higher than the values of $29-35 \mathrm{~mol} \%$ which were determined for $R$. anatipestifer by Segers et al. (1993).

From this polyphasic approach, it is demonstrated that the $R$. anatipestifer-like strains belong to the genus Riemerella and constitute a separate species for which the name $R$. columbina is proposed. The species name reflects the narrow host range, pigeons, from which all currently described members of this taxon were isolated. An emended genus description is based on data from Hinz et al. (1998a, b), Segers et al. (1993), Bernardet et al. (1996) and the present study.

\section{Emended description of the genus Riemerella}

Riemerella cells are Gram-negative, nonsporulating and nonmotile rods $0.2-0.5 \mu \mathrm{m}$ wide and $1-2.5 \mu \mathrm{m}$ long. All strains grow microaerobically and most of them aerobically on blood agar. Some strains grow anaerobically at $37^{\circ} \mathrm{C}$. Colonies are smooth, nonpigmented or greyish-white to beige pigmented. Growth on litmus lactose agar is strain-dependent, no growth is obtained on MacConkey's agar. Most strains show a positive Voges-Proskauer reaction. Nitrates are not reduced. Reaction for acid production from glucose is frequently negative in peptone-containing media. Activity of the following enzymes is present: oxidase, catalase, gelatinase, $\alpha$-glucosidase, $\alpha$-maltosidase, alkaline and acid phosphatase, esterase lipase $\mathrm{C} 8$, esterase $\mathrm{C} 4$, naphthol-AS-Bl-phosphohydrolase, leucine arylamidase, valine arylamidase, cystine arylamidase and L-aspartic acid arylamidase. The fol- 
lowing reactions are strain-dependent: urease, chymotrypsin, trypsin and arginine dihydrolase activity, indole production, haemolysis on blood, aesculin hydrolysis. Depending on the micro-test kit used, the following enzyme reactions give variable results: $\beta$ glucosidase, $\alpha$-galactosidase and lipase activity (these three reactions were all positive in the API ID32E and negative in the API ZYM system) and $N$-acetyl- $\beta$ glucosaminidase [negative in API ZYM and API ID32E, positive in LRA-ZYM-OSIDASES (Hinz et al., 1998b); only some representative $R$. anatipestifer strains were tested using the latter system]. Activity of the following enzymes is absent: chondroitin sulfatase, hyaluronidase, $\beta$-galactosidase, $\beta$-glucuronidase, $\alpha$ mannosidase, $\alpha$-fucosidase, trypsin, ornithine and lysine decarboxylase. None of the strains used malonate as a carbon source, or assimilated in the API $20 \mathrm{NE}$ system D-glucose, L-arabinose, D-mannose, Dmannitol, $N$-acetylglucosamine, maltose, D-gluconate, caprate, adipate, L-malate, citrate or phenyl acetate. No acid production was detected from D- and Larabitol, galacturonate, 5-ketogluconate, phenol red, D-mannitol, maltose, adonitol, palatinose, saccharose, L-arabinose, trehalose, rhamnose, inositol, sorbitol or cellobiose in the API ID32E system. Using the BSS test, however, acidification of the following carbohydrates may be detected: D-glucose, maltose, Dmannose and dextrin, and to a lesser extent $\mathrm{D}$-fructose, L-sorbose and trehalose. No acid was produced from lactose, D-galactose, $\quad N$-acetyl-D-glucosamine, lactulose, trehalose, saccharose, D-mannitol, L-arabinose, myo-inositol, D-sorbitol, D-xylose, dulcitol, salicin or adonitol. The genus is a member of the family Flavobacteriaceae. The closest phylogenetic neighbours are the genera Chryseobacterium and Bergeyella. Menaquinone-6 is the major respiratory quinone detected in the type species. The dominant fatty acids are the branched-chain fatty acids 13:0 iso, 15:0 iso, 15:0 anteiso, 15:0 iso $3-\mathrm{OH}$ and 17:0 iso $3-\mathrm{OH}$. Isolated mainly from diseased birds, in a few cases from pigs. The illness caused by the organism is a septicaemic disease in ducks, pigeons and other domestic and wild birds. The type species is $R$. anatipestifer. The DNA $\mathrm{G}+\mathrm{C}$ composition ranges from 29 to $37 \mathrm{~mol} \%$.

\section{Description of Riemerella columbina sp. nov.}

Riemerella columbina (co.lum.bi'na. L. fem. adj. columbina pertaining to pigeons).

The description of $R$. columbina is as for the genus, with the following specifications which allow differentiation of the newly described species from the type species $R$. anatipestifer. On Columbia blood agar, all strains showed good growth when incubated aerobically at $37^{\circ} \mathrm{C}$ and microaerobically at 24,37 and $42^{\circ} \mathrm{C}$ and produced a grey-white or beige pigment $(R$. anatipestifer strains are nonpigmented). None of the strains grew anaerobically at $37^{\circ} \mathrm{C}$ and no growth was observed on litmus lactose agar (variable features for $R$. anatipestifer strains). All strains tested hydrolysed aesculin (negative for $R$. anatipestifer strains). When using the API ID32E system, all strains showed a positive $\beta$-glucosidase activity (negative for $R$. anatipestifer strains; this reaction was, however, negative for $R$. columbina strains in the API ZYM system). None of the strains produced indole and all strains showed chymotrypsin activity (variable reactions for $R$. anatipestifer strains). Using the BSS test, all strains produced acid from D-glucose, maltose, D-mannose and dextrin (variable reactions for $R$. anatipestifer). A variable reaction (negative or weakly positive reaction) was obtained for the acid production of $D$-fructose and L-sorbose. The dominant fatty acid content consists of the branched-chain fatty acids 13:0 iso, 13:0 anteiso, $15: 0$ iso, $15: 0$ anteiso, $15: 0$ iso $3-\mathrm{OH}$ and $17: 0$ iso 3$\mathrm{OH}$ and 'summed feature 4'. Isolated from respiratory disease in pigeons. The type strain is LMG $11607^{\mathrm{T}}$, which was isolated from a pigeon palatine cleft in Germany. Its $\mathrm{G}+\mathrm{C}$ content is $36 \mathrm{~mol} \%$.

\section{ACKNOWLEDGEMENTS}

P.V. and K.K. are indebted to the Fund for Scientific Research Flanders (Belgium) for a position as a postdoctoral researcher and for research and personnel grants, respectively. Our research was also supported by the Prime Minister's Services - Federal Office for Scientific, Technical and Cultural Affairs, Belgium.

\section{REFERENCES}

Bernardet, J.-F., Segers, P., Vancanneyt, M., Berthe, F., Kersters, K. \& Vandamme, P. (1996). Cutting a Gordian knot: emended classification and description of the genus Flavobacterium, emended description of the family Flavobacteriaceae, and proposal of Flavobacterium hydatis nom. nov. (basonym Cytophaga aquatilis Strohl and Tait 1978). Int J Syst Bacteriol 46, 128-148.

Bøvre, K. (1984). Genus II. Moraxella Lwoff 1939, 173 emend. Henriksen and Bøvre 1968, 391 AL. In Bergey's Manual of Systematic Bacteriology, vol. 1, pp. 296-303. Edited by N. R. Krieg \& J. G. Holt. Baltimore: Williams \& Wilkins.

Brodgen, K. A. (1989). Pasteurella anatipestifer infection. In Pasteurella and Pasteurellosis, pp. 115-129. Edited by C. Adlam \& J. M. Rutter. London: Academic Press.

De Ley, J. (1970). Re-examination of the association between melting point, buoyant density, and chemical base composition of deoxyribonucleic acid. $J$ Bacteriol 101, 738-754.

De Ley, J., Cattoir, H. \& Reynaerts, A. (1970). The quantitative measurement of DNA hybridization from renaturation rates. Eur J Biochem 12, 133-142.

Hinz, K.-H., Ryll, M. \& Köhler, B. (1998a). Detection of acid production from carbohydrates by Riemerella anatipestifer and related organisms using the buffered single substrate test. Vet Microbiol (in press).

Hinz, K.-H., Ryll, M., Köhler, B. \& Glünder, G. (1998b). Phenotypic characteristics of Riemerella anatipestifer and similar microorganisms from various hosts. Avian Pathol 27, 33-42.

Lautrop, H. (1960). Laboratory diagnosis of whooping cough or Bordetella infections. Bull WHO 23, 15-31.

Mannheim, W. (1984). Family III. Pasteurellaceae POHL 1981a, 382. ${ }^{\mathrm{vP}}$. In Bergey's Manual of Systematic Bacteriology, vol. 1, 
pp. 550-557. Edited by N. R. Krieg \& J. G. Holt. Baltimore: Williams \& Wilkins.

Marmur, J. \& Doty, P. (1962). Determination of the base composition of deoxyribonucleic acid from its thermal denaturation temperature. J Mol Biol 5, 109-118.

Piechulla, K., Pohl, S. \& Mannheim, W. (1986). Phenotypic and genetic relationships of so-called Moraxella (Pasteurella) anatipestifer to the Flavobacterium/Cytophaga group. Vet Microbiol 11, 261-270.

Pot, B., Vandamme, P. \& Kersters, K. (1994). Analysis of electrophoretic whole-organism protein fingerprints. In Chemical Methods in Prokaryotic Systematics, pp. 493-521. Edited by M. Goodfellow \& A. G. O'Donnell. Chichester: Wiley.

Riemer (1904). Kurze Mitteilung über eine bei Gänsen beobachtete exsudative Septikämie und deren Erreger. Zentbl Bakteriol I Abt Orig 37, 641-648.

Rossau, R., Van Landschoot, A., Gillis, M. \& De Ley, J. (1991). Taxonomy of Moraxellaceae fam. nov., a new bacterial family to accommodate the genera Moraxella, Acinetobacter, and Psychrobacter and related organisms. Int J Syst Bacteriol 41, 310-319.
Segers, P., Mannheim, W., Vancanneyt, M., De Brandt, K., Hinz, K.-H., Kersters, K. \& Vandamme, P. (1993). Riemerella anatipestifer gen. nov., comb. nov., the causative agent of septicemia anserum exsudativa, and its phylogenetic affiliation within the Flavobacterium-Cytophaga rRNA homology group. Int $J$ Syst Bacteriol 43, 768-776.

Subramaniam, S., Chua, K.-L., Tan, H.-M., Loh, H., Kuhnert, P. \& Frey, J. (1997). Phylogenetic position of Riemerella anatipestifer based on 16S rRNA gene sequences. Int $J$ Syst Bacteriol 47, $562-565$.

Vandamme, P., Vancanneyt, M., Pot, B. \& 10 other authors (1992). Polyphasic taxonomic study of the emended genus Arcobacter with Arcobacter butzleri comb. nov. and Arcobacter skirrowii sp. nov., an aerotolerant bacterium isolated from veterinary specimens. Int J Syst Bacteriol 42, 344-356.

Vandamme, P., Segers, P., Ryll, M. \& 8 other authors (1998). Pelistega europaea gen. nov., sp. nov., a bacterium associated with respiratory disease in pigeons: taxonomic structure and phylogenetic allocation. Int $J$ Syst Bacteriol 48, 431-440.

Van Landschoot, A. \& De Ley, J. (1983). Intra- and intergeneric similarities of the rRNA cistrons of Alteromonas, Marinomonas (gen. nov.) and some other Gram-negative bacteria. J Gen Microbiol 129, 3057-3074. 